\title{
Evaluation of Oxidative Status of Patients with Gout Attack in a Cameroonian Urban Hospital
}

\section{Jan René Nkeck ${ }^{1}$ Madeleine Singwé-Ngandeu ${ }^{1,2}$, Vicky Ama Moor ${ }^{1,3}$, Jean-Pierre Chedjou ${ }^{4}$, Marie-Sollange Doualla1, Wilfred F. Mbacham ${ }^{1,4^{*}}$}

\author{
${ }^{1}$ Faculty of Medicine and Biomedical Sciences of the University of Yaoundé I, Yaoundé, Cameroon \\ ${ }^{2}$ Rheumatology unit of the Yaoundé Central Hospital, Yaoundé, Cameroon \\ ${ }^{3}$ Biochemistry laboratory of the Yaoundé University Hospital Centre, Yaoundé, Cameroon \\ ${ }^{4}$ Biotechnology Centre of the University of Yaoundé I, Yaoundé, Cameroon \\ Email: jrnkeck@gmail.com, ${ }^{*}$ wfmbacham@yahoo.com
}

How to cite this paper: Nkeck, J.R., Singwé-Ngandeu, M., Moor, V.A., Chedjou, J.-P., Doualla, M.-S. and Mbacham, W.F. (2017) Evaluation of Oxidative Status of Patients with Gout Attack in a Cameroonian Urban Hospital. Open Journal of Rheumatology and Autoimmune Diseases, 7, 111-119.

https://doi.org/10.4236/ojra.2017.72010

Received: April 1, 2017

Accepted: May 22, 2017

Published: May 25, 2017

Copyright (c) 2017 by authors and Scientific Research Publishing Inc. This work is licensed under the Creative Commons Attribution International License (CC BY 4.0).

http://creativecommons.org/licenses/by/4.0/

\section{(c) (i) Open Access}

\begin{abstract}
Background: Gout is the leading cause of microcrystalline arthritis worldwide and the most common cause of arthritis in adult men. The prevalence of cardiovascular disease, type II diabetes and metabolic syndrome is high among gout patients; one of the current hypotheses that may explain this relationship is based on oxidative stress; however, few studies have sought to investigate this relationship. Objective: The aim of this study was to determine the oxidative status of patients with gout attack. Methods: We conducted a case-control study over a 4 months period at the Rheumatology service of the Yaoundé Central Hospital. Cases were patients with an acute gout attack and controls were healthy subjects matched for sex and age. We evaluated uricemia, serum levels of Superoxide Dismutase (SOD), Glutathione Peroxidase (GPx), Catalase and Malondialdehyde (MDA). Oxidative stress was defined by an increase in MDA and/or a decrease in SOD, Catalase and GPx. Statistical analysis was performed by the S.P.S.S. 21.0 software. The Student's T-test was used to compare means; the significance threshold was 0.05 . Results: Sixty subjects were recruited of which 30 with an acute gout attack and 30 healthy subjects. The mean ages of the cases and controls were respectively $58 \pm 8$ years and $57.6 \pm 8$ years. Uricemia was statistically higher in cases $(81 \pm 20 \mathrm{mg} / \mathrm{L}) \mathrm{com}-$ pared to controls $(47 \pm 11 \mathrm{mg} / \mathrm{L})(\mathrm{p}<0.001)$. MDA levels were higher among cases $(1.37 \pm 0.46 \mathrm{mmol} / \mathrm{L})$ compared to controls $(1.14 \pm 0.39 \mathrm{mmol} / \mathrm{L})(\mathrm{p}<$ 0.05). There was no significant difference in serum levels of catalase, SOD and GPx between cases and controls. Conclusion: Patients with gout attack have an elevated serum level of malondialdehyde but their oxidative status seems similar to that of normal individuals.
\end{abstract}




\section{Keywords}

Gout, Oxidative Stress

\section{Introduction}

Gout is the leading cause of microcrystalline arthritis worldwide and the most common cause of arthritis in adult men [1]. It is caused by the precipitation of monosodium urate crystals in the joints and soft tissues and is one of the oldest diseases described in the medical literature [2]. In Cameroon, Singwé et al. in 2007 found that gout accounted for 5.9\% of patients consulting for rheumatologic diseases at a referral hospital in Yaoundé. Cameroonians who suffer from gout had clinical and paraclinical similarities with Caucasian populations [3]. Hyperuricemia is the major factor for the development of gout [4]. Several experimental, epidemiological and clinical studies have shown that hyperuricemia is associated to the development of high blood pressure, type II diabetes, chronic kidney disease, cardiovascular and cerebrovascular events [5] [6] [7]. Although the relationship between these conditions and hyperuricemia is not clearly established, it appears that the oxidative stress would be common to the pathogenesis of these disorders [8]. Oxidative stress is an imbalance between the oxidant and antioxidant factors of the body in favour of the oxidizing factors with formation of free radicals and other active oxygenated species; these free radicals will be responsible for the cellular damage, leading to aging, increasing cardiovascular risk and promoting many ailments [9]. Uric acid has been described in several studies in Caucasian and Indonesian populations as having an antioxidant but also a pro-oxidant effect [8] [10] [11]. The relationship between hyperuricemia, gout and oxidative stress is therefore not clearly established, so it appears important to evaluate the oxidative status of subjects with gout in order to contribute to the improvement of knowledge on the issue.

\section{Materials and Methods}

We conducted a case-control study over a 4 months' period from the $4^{\text {th }}$ January to the $4^{\text {th }}$ May 2016.

\subsection{Study Population}

Cases were adult volunteers with an acute gout attack diagnosed according to the ACR criteria of 1977 [12]. Participants were recruited from the emergency department and the internal medicine units of the Yaoundé Central Hospital in Cameroon. Were excluded any participants with non-gouty arthritis and/or with an impaired renal function assessed by a glomerular filtration rate less than 60 $\mathrm{mL} / \mathrm{min} / 1.73 \mathrm{~m}^{2}$ of body surface area, calculated by the MDRD formula (Modification of Diet in Renal Disease) with 4 parameters (race, sex, age, serum creatinine) [13]. A patient with an acute gout attack was defined as an acute arthritis 
(duration less than 3 weeks) with 01 major criteria or at least 6/12 minor criterion of the ACR 1977 [12]. A chronic gout patient had at least 03 attacks of gout per year and/or one or several tophus(i), and/or signs of chronic urate arthropathy, and/or urate nephropathy [12].

Controls were adults volunteers free of gout, recruited from the Cameroonian general population and matched to cases according to sex and age ( \pm 2 years) for a ratio of 1:1. Were excluded participants with impaired renal function assessed by a glomerular filtration rate below $60 \mathrm{~mL} / \mathrm{min} / 1.73 \mathrm{~m}^{2}$ of body surface area assess using MDRD formula [13].

Were not included in this study (for the group of cases as well as controls), any person known to be affected by at least one pathology that can modify uricemia or be a source of oxidative stress (chronic kidney disease, treated or not dyslipidemia, treated or not cancer, treated or not chronic inflammatory disease, known hemoglobinopathy, known acute or chronic Infection); we also did not include any person who took a drug altering uricemia within 30 days preceding the visit, consuming tobacco and/or alcohol; carrying out regular intense physical activity, taking contraceptives.

\subsection{Sample Size}

Was estimated using Withley et al. formula to compare proportions in case control study [14]. The power was set at $80 \%$.

\subsection{Sampling}

We proceeded by a non-exhaustive consecutive sampling.

\subsection{Procedure}

Every recruited participant was asked about the history of the gout and personal past history was sought. Physical examination was carried out in the course of which we took temperature, blood pressure, weight, size, abdominal circumference and a general exam was done looking for signs of gout and co-morbidities.

\subsection{Blood Sample Collection}

At the end of the interview a sample of $5 \mathrm{~mL}$ peripheral venous blood without tourniquet was drawn and put in dry and sterile Vacutiner ${ }^{\circledast}$ tubes. The blood sample was centrifuged at 3000 rotations per minute for 5 minutes at $25^{\circ} \mathrm{C}$ elsius and the serum collected was placed in dry type Eppendorf ${ }^{\bullet}$ tubes.

\subsection{Biochemical Analysis}

The biological parameters which were evaluated were uricemia, serum creatinine and serum levels of markers of oxidative stress namely superoxide dismutase (SOD), glutathione peroxidase (GPx), the malondialdehyde (MDA) and catalase.

The dosage of uricemiawas achieved within 24 hours by the enzymatic and colorimetric uricase method [15]. Hyperuricemia was defined by a rate of uric 
acid above $70 \mathrm{mg} / \mathrm{L}$ for men and $60 \mathrm{mg} / \mathrm{L}$ for women [1].

The dosage of serum creatinine was made within 24 hours of sampling by the Jaffé kinetic method [16].

The activity of MDA was determined by the method described by Wilbur in 1948 [17], which is based on the fact of heating 1 mole of MDA and 2 moles of thiobarbituric acid (TBA) in acid conditions gives a mixture of pink color whose absorbance can be measured at $532 \mathrm{~nm}$. The activity of the MDA was expressed as $\mu \mathrm{mol} / \mathrm{L}$.

The activity of SOD was determined by Misra and Fridovich's method (1972) [18], which is based on the inhibition of adrenaline oxidation to adrenochrome by SOD. SOD's activity was expressed in $\mathrm{n} U \mathrm{U} / \mathrm{min} / \mathrm{mg}$ of proteins.

The activity of GPx was determinedby the enzymatic method of Sigma-Aldrich, which uses pyrogallol as a substrate [19]; The GPx activity was expressed in IU/min/mg of proteins.

The activity of catalase was determined by the Sinha method (1972) [20], which is based on the fact that catalase separates $\mathrm{H}_{2} \mathrm{O}_{2}$ in water, but its activity is inhibited by the dichromate/acetic acid. The remaining $\mathrm{H}_{2} \mathrm{O}_{2}$ of the mixture reacts with the dichromate/acetic acid to form an unstable blue precipitate. This precipitate is broken down into a green solution whose absorbance at $570 \mathrm{~nm}$ is proportional to the volume of $\mathrm{H}_{2} \mathrm{O}_{2}$ remaining in the mixture. The catalase activity was expressed in IU/min/mg of proteins.

\subsection{Oxidative Stress}

It was defined for cases compared to controls by an increase in levels of malondialdehyde and decrease in antioxidants serum levels (Catalase, Superoxide dismutase, Glutathione peroxidase).

\subsection{Statistical Analysis}

Data were entered and coded in the CSPro software version 6.0; then extracted to S.P.S.S. software version 21.0 for statistical analysis. Quantitative variables were expressed in terms of mean and standard deviation. Qualitative variables were expressed in terms of counts and their proportions. The comparison of means of quantitative variables between the two groups was done by the Student's T-test after groups tested for their normality. The threshold of significance was set at 0.05 .

\section{Results}

Overall a total of 60 subjects were recruited, including 30 subjects with an acute gout attack and 30 control subjects. The average age of gout patients was $58 \pm 8$ years that of the controls was $57.6 \pm 8$ years. People affected by gout had over 50 years (90\%) and the most represented age group was 50 to 60 years (53\%) (Table 1 ). The sex ratio of gout patients was 14:1. Out of the patients with an acute gout attack, $21(73 \%)$ had an acute gout attack on chronic gout. The comorbidities frequently found in gout patients were hypertension (90\%), abdominal obesity 
(43\%) and general obesity (33\%) (Table 2).

The average uricemia of cases $(81 \pm 20 \mathrm{mg} / \mathrm{L})$ was statistically higher than that of the controls $(47 \pm 11 \mathrm{mg} / \mathrm{L})$ with a value $\mathrm{p}<0.001$ (Table 1 ). A quarter $(26 \%)$ of patients with an acute gout attack had a normal uricemia.MDA levels were statistically higher among cases $(1.37 \pm 0.46 \mu \mathrm{mol} / \mathrm{L})$ compared to the controls $(1.16 \pm 0.39 \mu \mathrm{mol} / \mathrm{L})$ with a $\mathrm{p}$-value $<0.05$ (Table 1$)$. There was no statistically significant difference in serum levels of SOD, GPx and catalase between cases and controls (Table 1).

\section{Discussion}

Gout is a metabolic disease and a frequent cause of acute and chronic pain in adults. It is associated with much co-morbidity. Our study aimed to evaluate the oxidative status of patients with an acute gout attack. The results of this study show an increase in MDA levels in gout patients. Having excluded the main factors of oxidative stress in these patients, these results suggest that gout attack not lead to an oxidative stress. Gout affects more people over the age of 50 years with an average of $58 \pm 8$ years, it is indeed it is the leading cause of arthritis in men over 40 years [4]. These values are close to the data obtained by Singwé et al. in Yaoundé in 2007, as well as those of Kemta et al. in 2014 who found a mean age of gout patients of $55.74 \pm 10.38$ years and $54.45 \pm 10.22$ [21] [22] respectively.

Table 1. Baseline Characteristics of each group.

\begin{tabular}{cccc}
\hline Parameters & Cases (30) & Controls (30) & P value \\
\hline Age (years) & $58 \pm 8$ & $57.8 \pm 8$ & $\mathrm{p}>0.05$ \\
Sex ratio (male/female) & $14: 1$ & $14: 1$ & \\
Body mass Index (Kg/m $\left.{ }^{2}\right)$ & $28.61 \pm 4.5$ & $27.25 \pm 4.6$ & $\mathrm{p}>0.05$ \\
Systolic blood pressure (mmHg) & $138 \pm 17$ & $132 \pm 20$ & $\mathrm{p}>0.05$ \\
Diastolic blood pressure (mmHg) & $85 \pm 9$ & $81 \pm 10$ & $\mathrm{p}>0.05$ \\
Uric acid (mg/L) & $81.19 \pm 20.95$ & $47.69 \pm 11.84$ & $\mathrm{p}<0.001^{*}$ \\
Malondialdehyde ( $\mu$ mol/L) & $1.37 \pm 0.46$ & $1.14 \pm 0.39$ & $\mathrm{p}<0.05^{*}$ \\
Catalase (IU/min/mg of proteins) & $831.07 \pm 154.09$ & $890.29 \pm 160.30$ & $\mathrm{p}>0.05$ \\
Superoxide dismutase & $128.07 \pm 79.24$ & $111.29 \pm 69.86$ & $\mathrm{p}>0.05$ \\
(nUI/min/mg of proteins) & & & \\
$\begin{array}{c}\text { Glutathione peroxidase } \\
\text { (IU/min/mg of proteins) }\end{array}$ & $0.0318 \pm 0.0125$ & $0.033 \pm 0.011$ & $\mathrm{p}>0.05$ \\
\hline
\end{tabular}

*Significant data.

Table 2. Comorbidities in gout patients.

\begin{tabular}{cccc}
\hline Comorbidities & Men $(\mathbf{n}=\mathbf{2 8})$ & Women $(\mathbf{n}=\mathbf{2})$ & Total (n= 30) \\
\hline Diabetes & $5(17.85 \%)$ & $2(100 \%)$ & $7(23.3 \%)$ \\
Hypertension & $26(92.85 \%)$ & $1(50 \%)$ & $27(90 \%)$ \\
Abdominal obesity & $12(42.85 \%)$ & $1(50 \%)$ & $13(43.33 \%)$ \\
General obesity & $9(32.14 \%)$ & $1(50 \%)$ & $10(33.33 \%)$ \\
\hline
\end{tabular}


Men are more affected by gout with a sex ratio of 14:1 as found by Singwé et al. (29:3) in 2007. However, it is lower than that found by Kemta et al. (26:6) in 2014 in Douala [21] [22]. This difference can be explained by our sample size which was smaller but also the differences in feeding and sex distribution of our original population. Gout patients are most often hypertensive, diabetic and obese. The metabolic syndrome is known to be at the origin of uric acid overproduction and decreased urinary excretion [23]. This association was also found by Kemta et al., Singwé et al. in cameroonians [21] [22]. Uric acid levels were statistically higher among cases compared to controls $(\mathrm{p}<0.01)$. Indeed, hyperuricemia is the main factor in development of gout [4]. However, some patients had a normal uricemia during the acute gout attack (23\%). Indeed, when the uric acid present in the blood precipitates in the form of urate crystals that will be deposited in the joints causing the acute attack, there will be a relative decrease in serum levels of uric acid [4]. This result is similar to that found by Singwé et al., Kemta et al. [21] [22]. Serum levels of Superoxide dismutase and Glutathione peroxidase were statistically similar for cases and controls. This result differs from that of Chetan et al. who found rates of Superoxide dismutase and Glutathione peroxidase significantly lower in subjects with an acute gout attack compared to healthy subjects $(\mathrm{p}<0.01)$ [8]. This difference can be explained by several factors: 1) the status of patients who were newly diagnosed with gout in the study of Chetan and al unlike ours, where $73 \%$ of patients had an acute gout attack on chronic gout; 2) the racial differences of our study populations could influence the level of oxidative stress, genetics and eating habits being conditioned by racial origin, they play an important role in the pathogenesis of oxidative stress [9]; 3) when oxidative stress continues, there is a decrease in serum levels of Superoxide dismutase and Glutathione peroxidase which are antioxidants and are the first lines of the body's defense against oxidants. Oxidative stress during chronic gout would lead to long-term reduction in the serum levels of Superoxide dismutase and Glutathione peroxidase [24]; 4) the serum levels of Superoxide dismutase and Glutathione peroxidase are also reduced in case of poor supply of trace elements such as zinc, manganese and copper, which were not evaluated in our study [24]. The serum levels of Catalase in cases were also statistically similar to controls. However, malondialdehyde levels were higher among cases compared to controls $(\mathrm{p}<0.05)$. This result is similar to that found by Chetan et al. in 2014 [8]. Malondialdehyde is an oxidant, which reflects lipid peroxidation; high levels of Malondialdehyde alone may reflect oxidative damages to lipids in patients with gout who have a metabolic syndrome. These elevations of MDA levels alone may not reflect the inflammatory phenomena caused by urate crystals in the joints, but could be the result of the pro-oxidant activity of uric acid [15] [25]. This study reveals the existence of an increase in malondialdehyde levels alone in acute gout patients. It however has some limitations: 1) oxidative stress is not specific of gout, other factors could influence the oxidative status such as diet, psychosocial stress, inflammatory diseases of infra-clinic expression unknown to the patient; 2) the diagnostic criterion of gout which 
have their limits; 3) the dosage of trace elements.

\section{Conclusion}

Patients with acute gout have an elevated serum level of malondialdehyde but their oxidative status seems similar to that of normal individuals.

\section{Acknowledgements}

We acknowledge the entire contribution of doctors, residents, medical students and nurses at the Yaoundé Central Hospital; the personnel of the biochemistry laboratory of the Yaoundé University Hospital Centre; the $\mathrm{PhD}$ students of the biochemistry laboratory of the Biotechnology Centre of the University of Yaoundé I; all the people who took part in this study.

\section{Funding}

This research did not receive fund from any organization. All the authors contributed to buying reagents.

\section{Authors' Contributions}

JRN, MSN and WFM designed the study. JRN, VAM, MSN and MSD built and revised the manuscript; JRN recruited the patients and did the clinical exam; JRN, VAM and JPC carried out the study and collected data; JRN analyzed the data. All the study was done under the supervision of WFM who was the source of most of the funding among all the authors. All authors read and approved the final manuscript.

\section{Competing Interest}

The authors declare there is no competing interest.

\section{Consent for Publication}

Not applicable.

\section{Ethics Approval and Consent to Participate}

All the patients read and signed an informed consent sheet. Research authorizations were obtained from the institutions concerned. Ethical clearance was obtained from the Institutional Ethical Review Board (IERB) of the Faculty of medicine and Biomedical Sciences of the University of Yaoundé I (Cameroon).

\section{References}

[1] Michael, A. and Becker, M.J. (2006) Hyperuricemia and Associated Diseases. Rheumatic Diseases Clinics of North America, 32, 275-293. https://doi.org/10.1016/j.rdc.2006.02.005

[2] Martinon, F. and Glimcher, L. (2006) Gout: New Insights into an Old Disease. The Journal of Clinical Investigation, 116, 2073-2075. https://doi.org/10.1172/JCI29404

[3] Singwe-Ngandeu, M., Meli, J., Ntsiba, H., Nouédoui, C., Yollo, A.V., Sida, M.B., et 
al. (2007) Rheumatic Diseases in Patients Attending a Clinic at a Referral Hospital in Yaoundé, Cameroon. East African Medical Journal, 84, 404-409.

[4] Rothschild, M. (2015) Gout and Pseudogout. http://emedicine.medscape.com/

[5] Alper Jr., A.B., Chen, W., Yau, L., Srinivasan, S.R., Berenson, G.S. and Hamm, L.L. (2005) Childhood Uric Acid Predicts Adult Blood Pressure: The Bogalusa Heart Study. Hypertension, 45, 34-38. https://doi.org/10.1161/01.HYP.0000150783.79172.bb

[6] Johnson, R.J., Segal, M.S., Srinivas, T., Ejaz, A., Mu, W. and Roncal, C. (2005) Essential Hypertension, Progressive Renal Disease, and Uric Acid: A Pathogenetic Link? Journal of the American Society of Nephrology, 16, 1909-1909. https://doi.org/10.1681/ASN.2005010063

[7] Nakanishi, N., Okamoto, M., Yoshida, H., Matsuo, Y., Suzuki, K. and Tatara, K. (2003) Serum Uric Acid and Risk for Development of Hypertension and Impaired Fasting Glucose or Type II Diabetes in Japanese Male Office Workers. European Journal of Epidemiology, 18, 523-530. https://doi.org/10.1023/A:1024600905574

[8] Acharya, C., Sharma, A. and Kantharia, N. (2014) Involvement of Oxidative Stress in Patients of Gout and Antioxidant Effect of Allopurinol. International Journal of Medical Science and Public Health, 4, 168-172. https://doi.org/10.5455/ijmsph.2015.0310201435

[9] Betteridge, D. (2000) What Is Oxidative Stress? Metabolism-Clinical and Experimental, 49, 3-8. https://doi.org/10.1016/S0026-0495(00)80077-3

[10] Kolz, M., Johnson, T., Sanna, S., Teumer, A., Vitart, V. and Perola, M. (2009) MetaAnalysis of 28,141 Individuals Identifies Common Variants within Five New Loci That Influence Uric Acid Concentrations. PLoS Genetics, 5, e1000504. https://doi.org/10.1371/journal.pgen.1000504

[11] Shah, A. and Keenan, R.T. (2010) Gout, Hyperuricemia, and the Risk of Cardiovascular Disease: Cause and Effect? Current Rheumatology Reports, 12, 118-124. https://doi.org/10.1007/s11926-010-0084-3

[12] Neogi, T., Jansen, T.L.T.A., Dalbeth, N., Fransen, J., Schumacher, H.R. and Berendsen, D. (2015) 2015 Gout Classification Criteria: An American College of Rheumatology/European League against Rheumatism Collaborative Initiative. Annals of the Rheumatic Diseases, 74, 1789-1798. https://doi.org/10.1136/annrheumdis-2015-208237

[13] Levey, A.S., Bosch, J.P., Lewis, J.B., Greene, T., Rogers, N. and Roth, D. (1999) A More Accurate Method to Estimate Glomerular Filtration Rate from Serum Creatinine: A New Prediction Equation. Annals of Internal Medicine, 130, 461-470. https://doi.org/10.7326/0003-4819-130-6-199903160-00002

[14] Whitley, E. and Ball, J. (2002) Statistics Review 4: Sample Size Calculations. Critical Care, 6, 335-341. https://doi.org/10.1186/cc1521

[15] Burtis, C.A., Ashwood, E.R. and Bruns, D.E. (2012) Tietz Textbook of Clinical Chemistry and Molecular Diagnostics. Elsevier Health Sciences, 4775 p.

[16] Kaplan, A. and Glucose, K. (1984) ClinChem. The CV Mosby Co., St Louis, Toronto, Princeton, $436 \mathrm{p}$.

[17] Janero, D. (1990) Malondialdehyde and Thiobarbituric Acid-Reactivity as Diagnostic Indices of Lipid Peroxidation and Peroxidative Tissue Injury. Free Radical Biology and Medicine, 9, 515-540.

[18] Paoletti, F., Aldinucci, D., Mocali, A. and Caparrini, A. (1986) A Sensitive Spectrophotometric Method for the Determination of Superoxide Dismutase Activity in 
Tissue Extracts. Analytical Biochemistry, 154, 536-541.

[19] Wheeler, C., Salzman, J.A., Elsayed, N., Omaye, S. and Korte, D. (1990) Automated Assays for Superoxide Dismutase, Catalase, Glutathione Peroxidase, and Glutathione Reductase Activity. Analytical Biochemistry, 184, 193-199.

[20] Sinha, A. (1972) Colorimetric Assay of Catalase. Analytical Biochemistry, 47, 389394.

[21] Singwe, N., Nouédoui, C., Sobngwi, E., Matike, M. and Juimo, G. (2009) La goutte en consultation hospitalière de rhumatologie à l'Hôpital Central de Yaoundé. Mali Médical, 24, 17-20.

[22] Kemta, L. and Doualla, M. (2015) Clinical Features of Women with Gout Arthritis in Cameroon, Central Africa. Annals of the Rheumatic Diseases, 74, 773-774.

[23] McAdams-DeMarco, M., Maynard, J., Coresh, J. and Baer, A. (2012) Anemia and the Onset of Gout in a Population-Based Cohort of Adults: Atherosclerosis Risk in Communities Study. Arthritis Research \& Therapy, 14, R193. https://doi.org/10.1186/ar4026

[24] Sies, H. (2015) Oxidative Stress: A Concept in Redox Biology and Medicine. Redox Biology, 4, 180-183.

[25] Yuri, Y. and Johnson, R. (2008) Uric Acid: The Oxidant-Antioxidant Paradox. Nucleosides, Nucleotides \& Nucleic Acids, 27, 608-619.

https://doi.org/10.1080/15257770802138558

\section{Abbreviations}

ACR: American College of Rheumatology;

CsPro: Census and Survey Processing;

GPx: Glutathione Peroxydase;

MDA: Malondialdehyde;

SOD: Superoxide dismutase;

SPSS: Statistical Package for Social Sciences.

\section{Submit or recommend next manuscript to SCIRP and we will provide best service for you:}

Accepting pre-submission inquiries through Email, Facebook, LinkedIn, Twitter, etc. A wide selection of journals (inclusive of 9 subjects, more than 200 journals) Providing 24-hour high-quality service

User-friendly online submission system

Fair and swift peer-review system

Efficient typesetting and proofreading procedure

Display of the result of downloads and visits, as well as the number of cited articles Maximum dissemination of your research work

Submit your manuscript at: http://papersubmission.scirp.org/

Or contact ojra@scirp.org 